\title{
Detection of pharmacological active compounds of the Asteraceae family and their chemotaxonomical implications
}

\author{
Maria Urbanska, Joanna Nawrot, Renata Dawid-Pac, Kinga Kaczerowska-Pietrzak, \\ Monika Morag, Lidia Ratajczak, Gerard Nowak
}

Department of Medicinal and Cosmetic Natural Products, Poznan Medical University of Sciences, Poland

Email address:

gnowak@ump.edu.pl (G. Nowak)

\section{To cite this article:}

Maria Urbanska, Joanna Nawrot, Renata Dawid-Pac, Kinga Kaczerowska-Pietrzak, Monika Morag, Lidia Ratajczak, Gerard Nowak. Detection of Pharmacological Active Compounds of the Asteraceae Family and their Chemotaxonomical Implications. Journal of Plant Sciences.

Vol. 2, No. 5, 2014, pp. 187-191. doi: 10.11648/j.jps.20140205.16

\begin{abstract}
It can be assumed that sesquiterpene lactones and natural phytosteroids (ecdysones) are the characteristic compounds of the plants from the Asteraceae family. They display certain pharmacological properties and thus are helpful in chemical descriptions of the Asteraceae tribes, subtribes and species. Also some phenolic glycosides found in genus Klasea Cass, and in genus Centaurea L. may be of medical and chemotaxonomical significance. Our studies on the species of the aforementioned taxons and the isolation of several compounds allowed for interesting conclusions of phytochemical and taxonomical nature.
\end{abstract}

Keywords: Asteraceae, Sesquiterpene Lactones, Syringin, Ecdysones, Arbutin, Chemotaxonomy

\section{Introduction}

Since 1975 the research on a plants from Asteraceae family have been conducted in our Department and during this time few dozens of new compounds were isolated and identified. At the moment, research's primary focus is on the analysis of chemical structure of Asteraceae plants, which can help to establish their correct taxonomy and/or be the reason to use them in the future as a raw material of medicinal properties.

After preliminary tests conducted on about twenty species, four of them were pointed out and chosen for more detailed isolation study as most interesting due to ongoing discussion concerning their classification (i.e. there are many problems with the delimitation of the genera as well as their division into subgenera) as well as their potential pharmacological properties. Those species are: Centaurea adjarica Alb. of subg. Hyalinella (Tzvel.) Tzvel., distinguished by ability to accumulate large quantities of sesquiterpene lactones [1], Klasea quinquefolia (M. Bieb.) Cass.- classified in the past to the Serratula L.- with large quantities of phenolic glycoside but no ecdysones, compounds present in another species: Serratula wolffii Andrae. The fourth species is Stizolophus balsamita (Lam.) Cass. ex Takht, in which sesquiterpene lactones (germacrane derivatives with the significant 4,5 epoxide in the structure, which is responsible for the anti-migraine effect) were found [2,3].

Thin layer chromatography (TLC) proved to be the most valuable method of preliminary identification of Asteraceae compounds. Thanks to TLC, it was possible to suggest a detailed description of the chemical structure of the isolated compounds. Basing on the colors on the chromatograms, the type of sesquiterpene lactones (e.g. germacranolides and guaianolides) and even the substituents, with the place of their attachment can be determined with high probability [4-7].

Sesquiterpene lactones have in general antimicrobial, antiprotozal and anti-inflammatory properties [8] while 4,5-epoxy-germacranolides can have anti-migraine effect by inhibition the release of serotonin (5-HT) from bovine platelets, probably the most important agent in the etiology of migraine [9].

The guaianolides occurring in the species of Centaureinae Dumort. Asteraceae subtribe and isolated in the laboratory of Department of Medicinal and Cosmetics Natural Products, Poznan Medical University of Sciences, were always accompanied by syringin (1). This phenolic glycosides (syn. eleutheroside B) were found to possess an 
immunomodulatory, anti-allergic and inhibitory on bone resorption effects [10].

In Klasea Cass. and Serratula L., however, neither sesquiterpene lactones nor syringin have been found so far, whereas ecdysones and arbutin (2) are characteristic for this taxones. Ecdysones have strengthening properties [11], while arbutin is believed to be responsible for the urinary tract's disinfection after hydrolysis to hydrochinon compound [12] and acts against hyperpigmentations such as: melasma, lentigines and ephelides [13].

Both ecdysones and arbutin are included as a chemotaxonomic factor in species of the Serratula and Klasea genus [14]. The glycoside compounds, sesquiterpene lactones as well as ecdysones, have specific place on chromatograms (revealing the presence of the hydroxyl groups in their structures) as well as distinctive colors, which set them apart easily from each other and any other Asteraceae compounds.

\section{Material and Methods}

\subsection{Plant Material}

Aerial parts of Centaurea adjarica, Klasea quinquefolia (syn. Serratula quinquefolia (M. Bieb) ex Wild.) Serratula wolffii and Stizolophus balsamita were collected from plants growing in the garden of Department of Medicinal and Cosmetic Natural Products, University of Medical Sciences in Poznan (Poland), where their voucher specimens are deposited.

\subsection{Extraction and Isolation}

Dry and crushed plant material (about 500g each) was extracted with methanol three times. A crude methanol $\left(\mathrm{CH}_{3} \mathrm{OH}\right)$ extracts from herbs of Centaurea adjarica, Klasea quinquefolia, Serratula wolffii, was a base for isolation of single compounds.

The $\mathrm{CH}_{3} \mathrm{OH}$ extract from the herbs of Stizolophus balsamita after the evaporation of the solvent, was dissolved with distilled water (ca. $600 \mathrm{~cm}^{3}$ ). The water was extracted with dichloromethane $\left(\mathrm{CH}_{2} \mathrm{Cl}_{2}\right)$. The $\mathrm{CH}_{2} \mathrm{Cl}_{2}$ extract, in turn, having been dried with anhydrous sodium sulphate, was used for thin layer chromatography and the isolation of single compounds.

The extracts were separated by column chromatography on silica gel (Merck Art. 7733). The fractions were subjected to repeated column chromatography on silica gel (Merck Art. 7729) and eluted by right mobile phases. The structures of the isolated compounds were identified on the basis of ${ }^{1} \mathrm{H}$ NMR and ${ }^{13} \mathrm{C}$ NMR spectroscopy (Varian, $600 \mathrm{MHz}$, in $\mathrm{CDCl}_{3}$ or $\mathrm{CD}_{3} \mathrm{OD}$ ), IR spectroscopy (PE-580, 4000-500 $\mathrm{cm}^{-1}$ ) and EI mass spectrometry (AMD-604,70eV), and by comparing the obtained data with those of the reference compounds or reported data [15-19].

\subsection{TLC Analysis}

TLC was performed at room temperature on glass or aluminium-backed silica gel plates DC Alufolien Kieselgel 60 (Merck Art. 5553). 15-20 $\mu \mathrm{g}$ of each isolated compounds were applied per plate. Developed and dried chromatograms were sprayed by anisaldehyde reagent and heated at $103^{\circ} \mathrm{C}$ for 3 minutes.

\section{Results}

A crude methanol $\left(\mathrm{CH}_{3} \mathrm{OH}\right)$ extracts from herbs of Centaurea adjarica, Klasea quinquefolia, Serratula wolffii, was a base for isolation respectively of: syringin (1), arbutin (2), polypodine B (3), ajugasterone C (4) and 20-hydroxyecdysone (5). Syringin (1) isolated from Centaurea adjarica is presented in this paper for the first time. (Fig.1).

The $\mathrm{CH}_{2} \mathrm{Cl}_{2}$ extract from the herbs of Stizolophus balsamita in turn, was used for the isolation of: balsamin (6), izospiciformin (7), stizolin (8), $8 \alpha, 9 \alpha$-dihydroxyparthenolide (9), 8 8 -(4'-hydroxy)senecioyloxy-9-hydroxyparthenolide (10) and stizolicin (11) (Fig. 1).
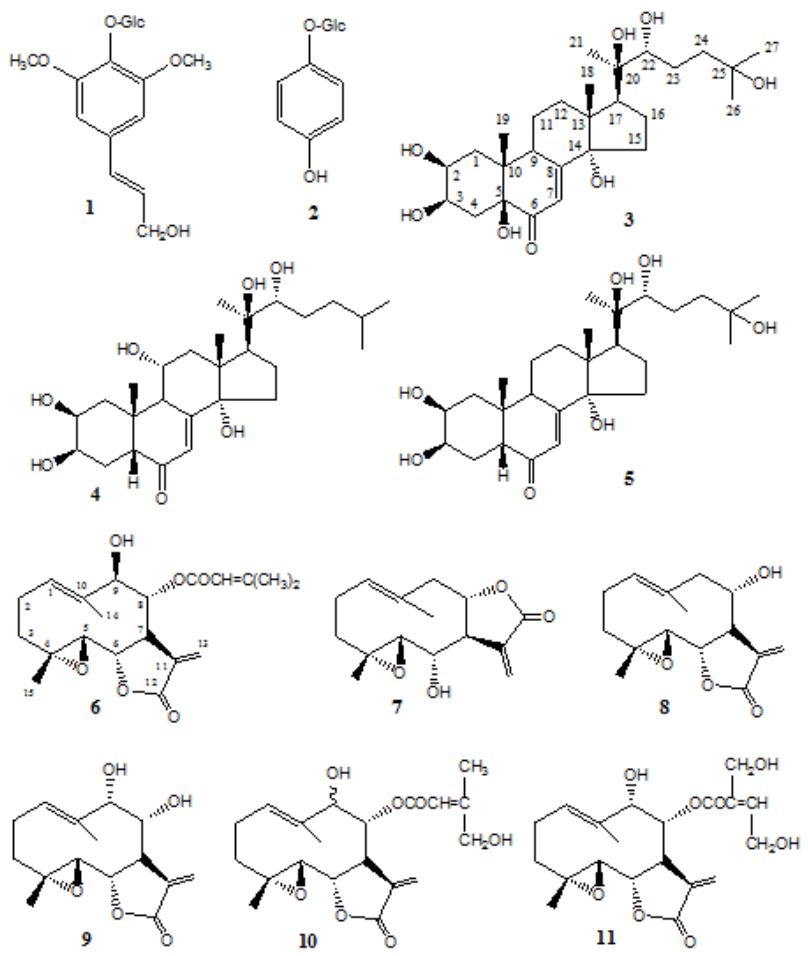

Figure 1. Structures of chromatographed compounds: 1. syringin; 2. arbutin; 3. polypodine B; 4. ajugasterone C; 5. 20-hydroxyecdysone; 6. balsamin; 7 . izospiciformin; 8 . stizolin; 9. $8 \alpha, 9 \alpha$-dihydoxyparthenolide; 10.

$8 \alpha$-(4'-hydroxy)senecioyloxy-9-hydroxyparthenolide; 11. stizolicin.

\subsection{TLC of the Compounds from Serratula wolffii Herb}

Of significance are the TLC results for the three most important Asteraceae ecdysones: polypodin B (3), ajugasterone C (4) and 20-hydroxyecdysone (5) which were found in Serratula wolffii. Compound 3 was changing its polarity depending on the presence of the solvents used to develop the chromatogram [6]. Moreover, only compounds 3 and 5 changed their color a few hours after being sprayed upon 
with the developer (Fig. 2).

$\mathrm{N}$-hexane - acetone $1: 4$ is the best mobile phase to separate ajugasterone $\mathrm{C}(4)$ from mixture of polypodin $\mathrm{B}$ (3) and 20-hydroxyecdysone (5) (Fig. 3) and dichloromethane methanol $6: 1$ is the best mobile phase to separate compounds 4 and 5 (Fig. 4).
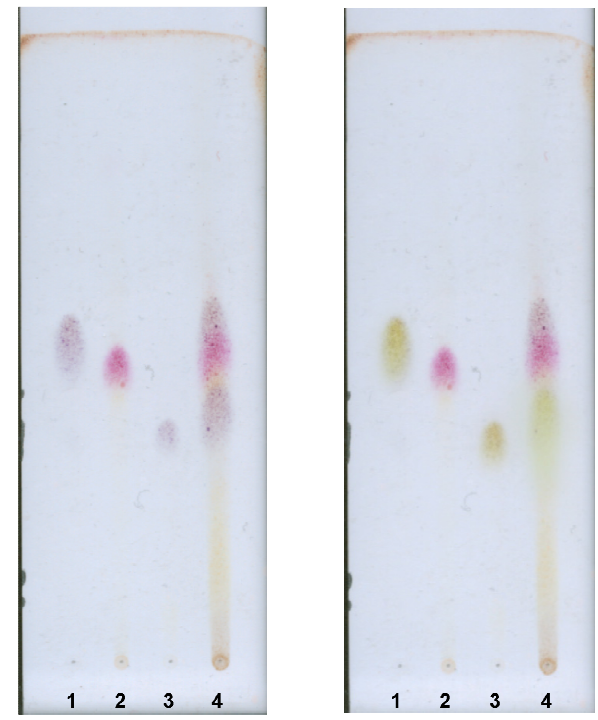

Figure 2. Color changes of Serratula wolffii ecdysones spots after a few hours 1. polypodine B (3); 2 ajugasterone $C$ (4); 3. 20-hydroxyecdysone (5); 4. Methanolic extract from Serratula wolffii herb. Mobile phase: dichloromethane-methanol 6:1.

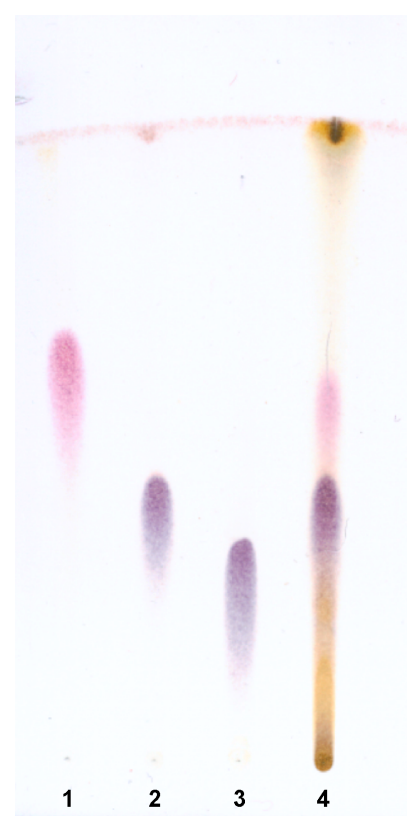

Figure 3. Chromatogram of ecdysones from Serratula wolffii: 1. Ajugasterone $C$ (4); 2. 20-hydroxyecdysone (5); 3. polypodine B (3); 4. Methanolic extract from Serratula wolffii herb. Mobile phase: $n$-hexane-acetone 1:4.

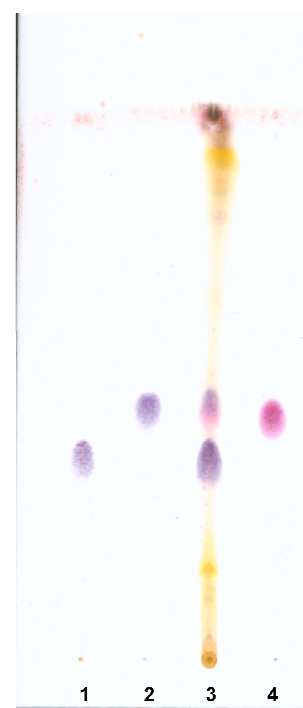

Figure 4. Chromatogram of ecdysones from Serratula wolffii: 1 . 20-hydroxyecdysone (5); 2. polypodine $B$ (3); 3. Methanolic extract from Serratula wolffii herb; 4. ajugasterone C (4); Mobile phase: dichloromethane - methanol 6:1.

\subsection{TLC of Phenolic Glycosides: Arbutin and Syringin}

Ecdysones are not present in Klasea quinquefolia. Instead $\beta$-arbutin was found (Fig. 5) and thus the conjectures about chemical differences between some species from the Serratula and Klasea genus were confirmed.

Centaurea adjarica is a species which synthesized large amounts of guaianolides [1] proportional to the concentration of syringin (1), with light blue color of the spot on the chromatogram (Fig.5).

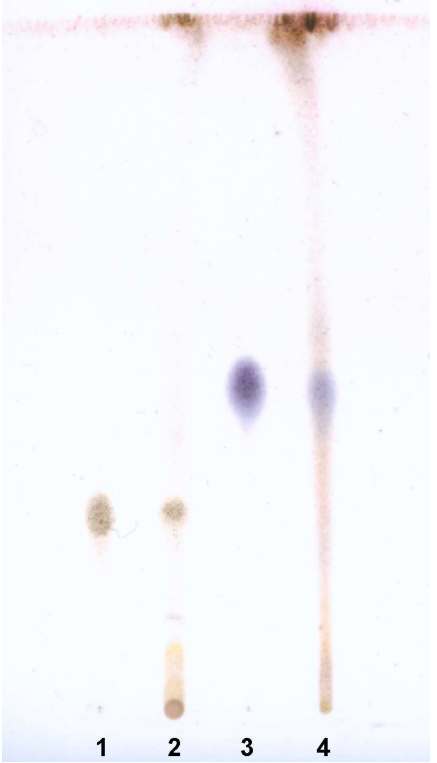

Figure 5. Chromatogram of phenolic glycosides from Klasea quinquefolia leaf and Centaurea adjarica herb: 1. Arbutin (1); 2. Methanolic extract from K. quinquefolia leaf; 3. Syringin (2); 4. Methanolic extract from C. adjarica herb. 


\subsection{TLC of Germacranolides from Stizolophus balsamita}

Upon spraying with the anisaldehyde reagent the compounds $6-11$ were isolated from the aerial parts of Stizolophus balsamita. The color of the spots of those germacranolides can be ascribed to the presence of several substituents at the carbon C8 and C9 [6]. Each of the four germacranolides: izospiciformin (7), stizolin (8), $8 \alpha, 9 \alpha$-dihydroxyparthenolide (9), and stizolicin (11) appeared as mauve spots on the chromatograms, apparently due to the above mentioned substituents: $\alpha-\mathrm{OH}$ substituent on $\mathrm{C} 9$ and ester/OH group on $\mathrm{C} 8$ (Fig. 6). Balsamin (6) on the other hand, appeared as a green colored spot which is determined by beta configuration of $\mathrm{OH}$ group on $\mathrm{C} 9$ (Fig.6). This may suggest that $8 \alpha$-(4'-hydroxy)senecioyloxy-9-hydroxyparthenolide (10) (which appeared as a green colored spot as well) has also $\beta$-OH group on $\mathrm{C}$.

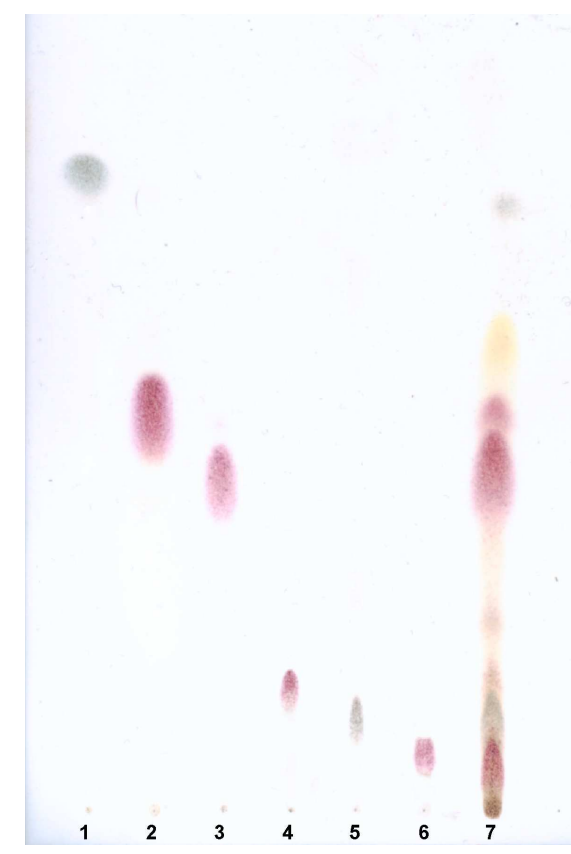

Figure 6. Chromatogram of sesquiterpene lactones from Stizolophus balsamita herbs: 1. balsamin (6); 2. izospiciformin (7); 3. stizolin (8); 4. $8 \alpha, 9 \alpha$-dihydoxyparthenolide (9);

$8 \alpha$-(4'-hydroxy)senecioyloxy-9-hydroxyparthenolide (10); 6. stizolicin (11); dichloromethane extract from Stizolophus balsamita. Mobile phase: dichloromethane - acetone 8:1.

\section{Discussion}

\subsection{General Conclusions}

Chemical structure of four significant species from four genera: Centaurea, Klasea, Serratula and Stizolophus analyzed with the TLC method was presented in this paper. Chromatograms of natural compounds isolated from this species are being published for the first time.

The difference in the chemical structure between Serratula (in which ecdysones are present) and Klasea (no ecdysones, arbutine present) was thus demonstrated and the methods of an isolation of biologically active compounds (among others separation of polypodine B from 20-hydroxyecdysone, which in the general phytochemists' opinion is not possible) were presented.

\subsection{This Study Results in the Light of Previous Research}

Two species: Klasea quinquefolia and Centaurea adjarica were previously analyzed in our Department of Medicinal and Cosmetic Natural Products. From Klasea quinqefolia leaf $\beta$-arbutin was isolated [14] and from Centaurea adjarica 15 sesquiterpene lactones from the guaianolide group were isolated [1], whereas the study presented in this paper for the first time determines the presence of syringin in this plant.

All natural compounds from Stizolophus balsamita were isolated before $[2,3]$ but the absolute structure of compound 10 was previously described as $8 \alpha-(4$ '-hydoxy)senecioyloxy-9 $\alpha$-hydroxyparthenolide [15]. whereas our research showed that it should be

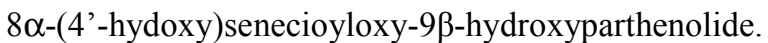

Previous research on Serratula wolffii was conducted mainly on its roots [19] whereas our study showed that it is actually Serratula wolffii herbs which are most efficient when the quantity of ecdysones $(3-5)$ is concerned.

\subsection{Medical Value of the Findings}

As opposed to previous studies during our research we were able to isolate large quantities of some natural compounds of Asteraceae. This factor allowed us to undertake following pharmacological studies which are now in progress: anti-fungial (Centaurea adjarica herb extract and isolated syringin), anti-hyperpigmentation (Klasea quinquefolia leaf - extract), anti-seborrheic dermatosis (Serratula wolffii herb - extract), anti-serotonin (Stizolophus balsamita herb - extract and isolated predominant compounds $-7,8,11$ ). Preliminary results of those studies are very optimistic. Additional to that research on the influence of the ecdysones 3-5 on the breast cancer cells.

\section{References}

[1] G. Nowak, B. Drożdż, M. Holub, M. Budesinsky, D. Saman. New guaianolides in Centaurea bella Trautv. and Centaurea adjarica Alb. Acta Soc. Bot. Pol. 1986;55: 227-231.

[2] G. Nowak, M. Drozdz, M. Budesinsky, M. Holub. Germacranolides in the genus Stizolophus Cass. Acta Soc. Bot. Pol. 1986;58: 247-251.

[3] M.N. Mukhametsanov, V.I Scheitschenko, K.S. Rybalko, D. Pakulin. A sesquiterpene lactones from Stizolophus balsamita. Khim. Prir. Soedin. 1971;7: 405-406.

[4] G. Nowak, R. Dawid-Pac, M. Urbanska J. Nawrot. TLC of selected sesquiterpenoids of the Asteraceae family. Acta Soc. Bot. Pol. 2011;80: 193-196.

[5] G. Nowak. Chromatography of twentysix sesquiterpene lactones from Centaurea bella. Chromatographia. 1993;35: 325-328. 
[6] G. Nowak, M. Urbanska, J. Nawrot, M.K. Bernard, R. Dawid-Pac. Color and Chemical Reactions of Selected Sesquiterpene Lactones and Ecdysones from Asteraceae on TLC Plates. Journal of Planar Chromatography. 2013;26: 289-293.

[7] G. Nowak. Thin Layer Chromatography of Guaianolides from Centaureinae Subtribe. Journal of Chromatography. 1990;505: 417-423.

[8] M. Bruno, S. Bancheva, S. Rosselli, A. Maggio. Sesquiterpenoids in subtribe Centaureinae (Cass.) Dumort (tribe Cardueae, Asteraceae: Distribution, 13C NMR spectral data and biological properties. Phytochemistry 2013; 95: 19-33.

[9] J.T. Arnason, R. Mata, J.T. Romeo. Recent advances in phytochemistry. Phytochemistry of Medicinal Plants. Plenum Press New York and London 1995; 29: 333-352.

[10] J. Cis, G. Nowak, M. Horoszkiewicz-Hassan, W. Kisiel. Syringin in some species of the subtribe Centaureinae of the Asteraceae. Acta Soc. Bot. Pol. 2003;72: 105-107.

[11] M. Bathori, Z. Pongracz. Phytoecdysteroids - from isolation and their effects on humans. Curr. Med. Chem. 2008;15:7 5-91.

[12] R.F. Weiss, V. Fintelmann. Herbal Medicine. 2nd edition. Thieme. Stuttgart, New York. 2000 p. 223.

[13] K. Maeda, M. Fukuda. Arbutin: mechanism of its depigmenting action in human melanocyte culture. J Pharmacol Exp Ther 1996; 276: 765-769.

[14] G. Nowak, J. Nawrot, K. Latowski. Arbutin in Serratula quinquefolia M.B. (Asteraceae). Acta Soc. Bot. Pol. 2009;78: 137-140.

[15] M. Budesinsky G. Nowak, U. Rychlewska, D,J, Hodogson D. Saman, W.M. Daniewski, B. Drozdz and M. Holub. Structure of Sesquiterpene Lactones of Some Species of Subtribe Centaureinae Dumort. Collect. Czech. Chem. Commun. 1994;59: 1175-1202.

[16] G. Nowak A Chemotaxonomic Study of Sesquiterpene Lactones from Subtribe Centaureinae of the Compositae. Phytochemistry. 1992;31: 2363-2368.

[17] M. Báthori, A. Gergely, H. Kalász, G. Nagy A. Dobos, I. Mathe. Liquid Chromatographic Monitoring of Phytoecdysteroid Production of Serratula wolffii. Journal of Liquid Chromatography \& Related Technologies 2000, 23 (2): 281-294.

[18] J. Nycz, G. Malecki, M. Morag, G. Nowak, L. Ponikiewski, J. Kusz. Arbutin: Isolation, X-ray structure and computional studies, Journal of Molecular Structure 2010; 980: 13-17.

[19] M. Takás, A. Simon, E. Liktor-Busa, M. Bathori, F. Zsila, P. Horvath, G. Veress, A. Gergely, G. Toth. Structure and stereochemistry of novel ecdysteroids from the roots of Serratula wolffii. Magnet Reson Chem 2010;48: 386-391. 